\title{
Pendistribusian Dana Zakat pada Program Beasiswa Satu Keluarga Satu Sarjana di Badan Amil Zakat Nasional Jawa Timur
}

\author{
Irsalina Almashuri, Bambang Subandi \\ Universitas Islam Negeri Sunan Ampel Surabaya \\ irsalinaalmashuri@gmail.com
}

Article Info

Keyword:

Pendistribusian,

Beasiswa, BAZNAS

Page: $30-42$

\begin{abstract}
This research aim to answer question. The question is regarding the implementation of zakat distribution to onefamily-one-bachelor scholarship program at National Amil Zakat of East Java. The researcher used qualitative approach, spesifically case study type. This research used interview, observation, and documentation as data collection techniques.

The finding of this research indicates that the distribution process at National Amil Zakat Institution of East Java is through transferring the zakat to Mustahik of one-familyone-bachelor scholarship program. BAZNAS that based in regency in East Java is a distribution channel to reach Mustahik outside Surabaya and Sidoarjo. Baznas that based in regency also distributes zakat to the mustahik through transfer as well. At this point, the distribution process in Baznas of East Java is directly distributed to mustahik.
\end{abstract}

Penelitian ini bertujuan untuk menjawab pertanyaan. Pertanyaan tersebut adalah bagaimana implementasi pendistribusian zakat pada program beasiswa satu keluarga satu sarjana di Badan Amil Zakat Nasional Jawa Timur. Peneliti menggunakan pendekatan kualitatif dan menggunakan jenis penelitian studi kasus. Penelitian ini menggunakan wawancara, observasi, dan dokumentasi untuk teknik pengumpulan data.

Penelitian ini menemukan, bahwa proses pendistribusian pada Badan Amil Zakat Nasional Jawa Timur adalah melalui transfer kepada mustahik penerima beasiswa SKSS. BAZNAS Kabupaten di provinsi Jawa Timur merupakan saluran distribusi untuk menjangkau mustahik diluar kota Surabaya dan Sidoarjo. BAZNAS Kabupaten ini juga akan menyalurkan dana zakat kepada mustahik penerima beasiswa melalui transfer. Dalam hal ini, pendistribusian pada BAZNAS Jawa Timur diberikan secara langsung kepada mustahik.

\section{Editorial Office:}

Program Studi Manajemen Dakwah, Fakultas Dakwah dan Komunikasi, UIN Sunan Ampel Surabaya. Jl. Ahmad Yani 117 Surabaya, Jawa Timur, Indonesia.

Email: jurnalilkom@uinsby.ac.id 


\section{Pendahuluan}

\section{A. Latar Belakang}

Menurut Kotler, distribusi adalah kelompok lembaga yang membuat sistem penyaluran. Penyaluran ini berupa barang atau jasa. Penyaluran barang atau jasa ini adalah untuk dipakai dan dikonsumsi oleh konsumen. ${ }^{1}$

Distribusi merupakan salah satu dimensi dari marketing. Pendistribusian dapat diartikan sebagai kegiatan marketing untuk mempermudah penyampaian barang dari produsen agar sampai kepada konsumen. Penyampaian barang ini dilakukan agar penggunaannya sesuai dengan keinginan dan keperluan konsumen. Hal tersebut adalah jumlah, jenis, harga, tempat dan waktu.

Dari pernyataan di atas dapat disimpulkan, bahwa pendistribusian merupakan kegiatan perusahaan untuk membuat konsumen mendapatkan produk yang diinginkan. Kegiatan ini dilakukan dengan memperkirakan kemudahan akses bagi konsumen. Perusahaan akan menyebarkan produknya kepada konsumen yang menjadi target pemasaran. Aktivitas penyebaran ini memperhitungkan kemudahan akses bagi konsumen.

Perusahaan membutuhkan bauran produk yang tepat. Kesuksesan produk bersandar pada distribusi. Kotler dan Armstrong menyatakan, bahwa produk adalah segala materi yang dapat dinegosiasikan ke pasar. Produk tersebut untuk memikat perhatian, penggunaan, dan

\footnotetext{
1 Muhammad Arif, Supply Chain Management, (Yogyakarta: Budi Utama, 2012), hal. 80

${ }^{2}$ Nembah F. Hartimbul Ginting, Manajemen Pemasaran (Bandung: Yrama Widya, 2011), hal. 90
}

konsumsi. Produk ini juga untuk memuaskan keinginan atau kebutuhan konsumen. $^{2}$

Perusahaan akan melihat produk apa yang dibutuhkan konsumen agar dapat dinikmati dan bermanfaat bagi konsumen. Keberhasilan suatu produk yang dipasarkan akan dipengaruhi oleh distribusi yang dilakukan oleh perusahaan tersebut.

Menurut Asri, produk merupakan kumpulan atribut umtuk memuaskan kebutuhan seseorang. Atribut tersebut berupa wujud nyata dan tidak. ${ }^{3}$ Kotler dan Lee mengatakan, bahwa produk merupakan segala sesuatu yang dapat ditawarkan kepada konsumen. Penawaran ini ditawarkan oleh organisasi atau individu. Produk yang ditawarkan tersebut untuk memenuhi kebutuhan atau keinginan dari konsumen. Produk yang ditawarkan kepada konsumen ini berbentuk barang dan jasa. Produk tersebut juga berupa penawaran tambahan dari organisasi atau lembaga yang sedang “dijual”. Penawaran tambahan dari organisasi ini berupa acara, orang (tokoh), tempat, organisasi itu sendiri, informasi, dan gagasan. ${ }^{4}$

Lembaga pengelola zakat milik pemerintahan adalah Badan Amil Zakat Nasional atau disebut BAZNAS. Distribusi pada BAZNAS adalah mendistribusikan dana zakat, infaq, dan sedekah. Distribusi zakat di BAZNAS Jawa Timur ini adalah untuk mengelola dan mendistribusikan dana zakat yang terkumpul.

\footnotetext{
${ }^{3}$ Marwan Asri, Marketing, (Yogyakarta: AMP YKPN, 1991), hal.204

${ }^{4}$ Philip Kotler dan Nancy Lee, Pemasaran di Sektor Publik, (Jakarta: Indeks, 2007), hal. 53
} 
BAZNAS Jawa Timur mempunyai berbagai program untuk menyalurkan dana zakat yang terkumpul kepada mustahik. BAZNAS Jawa Timur ini mempunyai lima macam program. Program yang dilakukan BAZNAS Jawa Timur ini merupakan produk yang ditawarkan kepada konsumen atau mustahik. BAZNAS Jawa Timur mempunyai cara tersendiri untuk menyalurkan dana zakat kepada mustahik yang disasar, yaitu sabilillah. Salah satu mustahik yang dipilih adalah mahasiswa kurang mampu, karena mereka termasuk orang yang berjuang di jalan Allah dengan mempelajari ilmu pengetahuan yang bermanfaat. Produk tersebut adalah Beasiswa Satu Keluarga Satu Sarjana.

Banyak keluarga yang anggotanya ingin meraih gelar sarjana. Hal tersebut dapat dilihat dari perjuangan pemuda zaman sekarang yang banyak mengantri mendaftar ujian masuk perguruan tinggi, namun tidak sedikit dari mereka yang tidak lolos dalam ujian tersebut. Orang-orang yang ingin melanjutkan ke perguruan tinggi tidak sedikit pula yang putus pendidikannya pada jenjang sekolah menengah atas, karena keterbatasan biaya.

Hal di atas dikarenakan keberadaan sarjana pada keluarga sangat penting untuk meningkatkan derajat dari suatu keluarga. Selain akhlak, orang lain akan memandang positif dari pendidikan yang dimiliki keluarga tersebut.

Penyaluran atau pendistribusian dana zakat adalah kegiatan penting untuk menyalurkan zakat dari muzakki kepada mustahik. Pendistribusian dana zakat tersebut disalurkan melalui beberapa program yang dilaksanakan BAZNAS Jatim. BAZNAS Jatim mendistribusikan dana zakat kepada mustahik fi sabilillah melalui Jawa Timur Cerdas. Program Jawa Timur Cerdas merupakan program yang bergerak dibidang pendidikan.

Dalam pelaksanaan program Jawa Timur Cerdas, BAZNAS Jatim menyalurkan zakat kepada mahasiswa kurang mampu melalui program beasiswa Satu Keluarga Satu Sarjana (SKSS). Syarat dari program beasiswa Satu Keluarga Satu Sarjana adalah belum terdapat sarjana dalam keluarga yang akan menerima beasiswa.

\section{B. Rumusan Masalah}

Berdasarkan latar belakang yang telah diuraikan di atas, maka permasalahan yang akan diangkat dalam penelitian ini adalah bagaimana implementasi pendistribusian zakat pada program beasiswa satu keluarga satu sarjana di badan amil zakat nasional jawa timur?

\section{Tujuan Penelitian}

Dengan adanya rumusan masalah yang telah ditentukan peneliti di atas, maka tujuan penelitian ini adalah untuk menggambarkan implementasi pendistribusian zakat pada program beasiswa satu keluarga satu sarjana di badan amil zakat nasional jawa timur.

\section{Manfaat Penelitian}

Berdasarkan tujuan penelitian yang hendak dicapai, maka penelitian ini diharapkan mempunyai manfaat teoritik ataupun praktis.

1. Manfaat Teoritik

a. Memberikan sumbangan pemikiran bagi lembaga di bidang pendistribusian.

b. Dapat menyampaikan pesan dakwah terkait urgensi manajemen dalam menunjang pelaksanaan ibadah zakat.

2. Manfaat Praktis 
a. Dapat menjadi gagasan bagi praktisi dalam dunia manajemen maupun lembaga pengelola zakat di bidang pendistribusian.

b. Dapat dijadikan bahan masukan, referensi, acuan, maupun landasan pemahaman bagi pihakpihak tertentu untuk praktek maupun penelitian lanjutan terhadap objek sejenis atau aspek lainnya yang belum tercakup dalam penelitian ini.

\section{Kajian Teori}

\section{A. Pendistribusian}

Distribusi menurut KBBI berasal dari bahasa Inggris, yaitu distribution yang berarti penyaluran. Secara terminologi, distribusi merupakan penyaluran, pengiriman, atau pembagian kepada beberapa orang atau ke beberapa tempat.

Menurut Kotler, distribusi adalah kelompok lembaga yang membuat sistem penyaluran. Penyaluran ini berupa barang atau jasa. Penyaluran barang atau jasa ini adalah untuk dipakai dan dikonsumsi oleh konsumen. ${ }^{5}$

Dapat disimpulkan, bahwa pendistribusian merupakan kegiatan pemasaran yang berupaya untuk memperlancar dan mempermudah dalam menyampaikan barang dan jasa. Upaya penyampaian ini adalah dari produsen kepada konsumen. Penyampaian ini juga agar sesuai dengan yang diperlukan oleh konsumen. ${ }^{6}$

Pendistribusian pada perusahaan mempunyai pihak-pihak yang

\footnotetext{
5 Muhammad Arif, Supply Chain Management, (Yogyakarta: Budi Utama, 2012), hal. 80

6 Fendy Tjiptono, Strategi Pemasaran, (Yogyakarta: ANDI, 2001), hal. 185

7 Ari Setiyaningrum, Jusuf Udaya, dan Efendi, Prinsip-Prinsip Pemasaran, (Yogyakarta: ANDI, 2015), hal. 158
}

berkontribusi pada penyampaian produk kepada konsumen. Pihak tersebut merupakan sebuah organisasi-organisasi yang saling berhubungan. Hal ini dilakukan agar produk sampai kepada pemakai terakhir atau konsumen. ${ }^{7}$ Saluran distribusi merupakan perangkat yang digunakan perusahaan untuk mengirimkan atau menghantarkan tawaran dari perusahaan dan tempat yang baik agar konsumen bisa menggunakannya. ${ }^{8}$

Organisasi-organisasi yang berada pada jalur saluran distribusi mempunyai beberapa fungsi. Fungsi tersebut adalah informasi, promosi, negosiasi, pesanan, pendanaan, pengambilan risiko, kepemilikan fisik, pembayaran, kepemilikan. ${ }^{9}$ Untuk mencegah pemilihan saluran distribusi yang tidak efektif dan efisien, perusahaan harus mempertimbangkan isu terkait dengan pemasaran. Jika perusahaan ingin mencapai hasil yang memuaskan, maka perusahaan harus memilih saluran distribusi yang cocok dan benar.

Keputusan saluran distribusi mempunyai keterkaitan penting terhadap waktu, tempat, dan proses yang ditawarkan oleh perusahaan. Terdapat empat keputusan yang perlu diketahui, yaitu keputusan tentang bagaimana dan dimana warga mengakses program dan jasa, keputusan tentang kapan masyarakat dapat mengakses, keputusan tentang waktu mengunggu, keputusan tentang suasana.

\footnotetext{
8 Nandan Limakrisna, Manajemen Pemasaran Teori dan Aplikasi dalam Bisnis, (Jakarta: Mitra Wacana Media, 2012), hal. 65

${ }^{9}$ Thamrin Abdullah dan Francis Tantri, Manajemen Pemasaran, (Jakarta: Grafindo, 2016), hal. 209
} 
Pada proses saluran distribusi, strategi distribusi tidak hanya selesai pada penentuan pengembangan saluran distribusi. Produsen juga harus memilih dan mengelola saluran distribusi dengan mempertahankan ikatan terhadap perantara dengan baik. Dengan mempertahankan ikatan dengan baik, perantara akan mengingat produk-produk yang disalurkan dan memasarkannya dengan baik pula.

Produsen juga harus mempertimbangkan secara cermat pengembangan saluran distribusi, karena tidak semua perantara memiliki kemampuan yang sama.

\section{B. Produk}

Kotler dan Lee mengatakan, bahwa produk merupakan segala sesuatu yang dapat ditawarkan kepada konsumen. Penawaran ini ditawarkan oleh organisasi atau individu. Produk yang ditawarkan tersebut untuk memenuhi kebutuhan atau keinginan konsumen. Produk yang ditawarkan kepada konsumen ini berbentuk barang dan jasa. Produk tersebut juga berupa penawaran tambahan dari organisasi atau lembaga yang sedang "dijual". Penawaran tambahan dari organisasi ini berupa acara, orang (tokoh), tempat, organisasi itu sendiri, informasi, dan gagasan. ${ }^{10}$ Menurut Setyaningrum, produk adalah himpunan atribut fisik dan jasa yang dibuat untuk memenuhi kepentingan dan keinginan dari konsumen. ${ }^{11}$

Dalam merancang produk jasa, perusahaan juga harus mempunyai lima karakteristik, ${ }^{12}$ yaitu:

${ }^{10}$ Philip Kotler dan Nancy Lee, Pemasaran $d i$ Sektor Publik, (Jakarta: Indeks, 2007), hal. 53

${ }^{11}$ Ari Setiyaningrum, Jusuf Udaya, dan Efendi, Prinsip-Prinsip Pemasaran, (Yogyakarta: ANDI, 2015), hal. 87
1. Kualitas

Kualitas digunakan konsumen untuk mengevaluasi dan membandingkan dengan produk jasa lainnya.

2. Fitur

Fitur dapat ditambah dan dikurangi tanpa mengubah ciri khas dari suatu produk.

3. Rancangan

Merancang produk jasa dengan penampilan yang unik.

4. Merek

Bertujuan untuk mengidentifikasi sebagai hak milik dari perusahaan.

5. Kemasan pada jasa

Mengacu pada cara perusahaan penggabungkan unsur-unsur dalam penawaran jasa, seperti kemasan jasa restoran juga bisa ditambahkan jasa pengantaran pesanan. ${ }^{13}$

Atribut produk jasa adalah elemenelemen yang digunakan untuk pengembangan dan sebagai pembeda produk jasa. Elemen-elemen ini memberikan nilai tambah, manfaat, dan menjadi bahan pertimbangan dari produk.

Dalam proses membedakan produk jasa dengan produk jasa lain, atribut jasa menjadi daya tarik tersendiri bagi konsumen. Cara lain untuk menarik konsumen adalah dengan mendesain atribut produk jasa agar berbeda dengan yang lain. Terdapat dua hal yang perlu diperhatikan dalam mendesain produk jasa. Hal-hal yang harus diperhatikan tersebut adalah:

1. Branding

${ }^{12}$ Didin Fatihudin dan Anang Firmansyah,

Pemasaran Jasa, (Yogyakarta: Deepublish, 2019), hal. 92

${ }^{13}$ Fandy Tjiptono, Pemasaran Jasa, (Yogyakarta: ANDI, 2014), hal. 113 
Brand atau merek adalah pemberian nama, simbol, tenda, ataurancangan untuk mengidentifikasikan produk jasa yang diproduksi perusahaan. Hal tersebut dimaksudkan untuk membedakan dari produk jasa kompetitor.

2. Brand equity

Brand equity atau ekuitas merek merupakan poin dari suatu merek, sejauh mana merek produk dapat meningkatkan loyalitas, meningkatkan nama, asosiasi merek yang kuat, kualitas, dan hubungan saluran. ${ }^{14}$

\section{Penelitian Terdahulu}

Penelitian ini mengkaji tentang Pendistribusian Dana Zakat melalui Program Beasiswa Satu Keluarga Satu Sarjana di Badan Amil Zakat Nasional Jawa Timur. Studi tentang pendistribusian dana zakat terdapat lima dimensi.

Pertama, studi mengenai pendistribusian dana zakat pada badan amil zakat nasional di Indonesia. Studi tersebut dikaji oleh Susilowati ${ }^{15}$, Agustina ${ }^{16}$, Bahrudin $^{17}$, dan Risnawati ${ }^{18}$. Terdapat persamaan diantara studi Agustina dan

\footnotetext{
${ }^{14}$ Didin Fatihudin dan Anang Firmansyah, Pemasaran Jasa, (Yogyakarta: Deepublish, 2019), hal. 95

${ }^{15}$ Handri Susilowati, "Pelaksanaan Pendistribusian Zakat di BAZNAS Sumsel", Skripsi (Palembang: Manajemen Pendidikan Islam UIN raden Fatah, 2018), hlm. 5

${ }^{16}$ Kukuh Dwi Agustina, "Penyaluran Dana Zakat di Badan Amil Zakat Nasional (BAZNAS) Kabupaten Kebumen Tahun 2015", Skripsi (Purwekerto: Akhwal Al-Syakhsyiah IAIN Purwekerto), hlm. 28 17 Makhfudl Bayu Bahrudin, "Efektifitas Penyaluran Zakat di BAZNAS Provinsi Jawa Timur", Skripsi (Surabaya: Ekonomi Syariah UIN Sunan Ampel, 2017), hlm. 69

${ }^{18}$ Risnawati, "Kajian Pengelolaan dan Penyaluran Dana di BAZNAS Provinsi Sulawesi Selatan", Skripsi (Makassar: Ekonomi Islam UIN Alauddin, 2018), hlm. 22
}

Risnawati. Persamaan tersebut terletak pada mustahik yang menjadi sasaran dari pendistribusian zakat. Agustina menjelaskan terdapat delapan asnaf yang menjadi sasaran pendistribusian zakat BAZNAS kabupaten Kebumen. Risnawati menjelaskan terdapat delapan asnaf yang menjadi sasaran pendistribusian zakat BAZNAS Sulawesi Selatan. Terdapat perbedaan diantara studi Susilowati dan Bahrudin. Perbedaan tersebut terletak pada mustahik yang menjadi sasaran dari pendistribusian dana zakat mereka. Susilowati menjelaskan terdapat delapan asnaf dalam BAZNAS Sumsel, namun BAZNAS Sumsel berfokus pada fakir, miskin, amil, muallaf, fi sabilillah, dan ibnu sabil. Bahrudin menjelaskan terdapat tiga asnaf yang menjadi perhatian BAZNAS Jatim di tahun 2017. Tiga asnaf tersebut adalah fakir, miskin, dan ibnu sabil.

Kedua, studi mengenai pendistribusian dana zakat pada lembaga amil zakat di Indonesia. Studi tersebut dikaji oleh Ardiansyah ${ }^{19}$, Hakim ${ }^{20}$, Afdloluddin $^{21}$, dan Wati ${ }^{22}$. Perbedaan studi mereka terletak pada tahapan dalam

19 M. Iqbal Ardiansyah, "Pendistribusian Zakat pada Lembaga Amil Zakat Infaq dan Shadaqah (LAZIS) Al-wasi' Universitas lampung”, Skripsi (Lampung: Manajemen dakwah UIN Raden Intan, 2018), hal. 52

${ }^{20}$ Edi Lukman Hakim, "Pola Distribusi Dana Zakat Lembaga Amil Zakat Infaq dan Shadaqah (LAZISMA) Masjid Agung Jawa Tengah", Skripsi (Semarang: Ekonomi Islam IAIN Walisongo, 2011), hal. 55

${ }^{21}$ Afdloluddin, "Analisis Pendistribusian Dana Zakat bagi Pemberdayaan Masyarakat(Studi Pola Lembaga Amil Zakat Dhompet Dhuafa Cabang Jawa Tengah)", Skripsi (Semarang: Ilmu Ekonomi Islam UIN Walisongo, 2015), hal. 92

${ }^{22}$ Tanti Indah Wati, "Metode Pengumpulan Zakat dengan Sistem ZISCO dan Media Online serta Pendistribusian Zakat di Yayasan Yatim Mandiri cabang Surakarta (Studi berdasarkan Undang- 
pendistribusian dana zakat. Aridansyah menjelaskan terdapat dua langkah untuk mendistribusikan dana zakat, yaitu melakukan survei dan interview kepada orang yang akan menerima zakat. Hakim menjelaskan terdapat tiga langkah, yaitu menentukan sasaran, menuangkan kedalam program-program, dan penganggaran kedalam program-program. Afdloluddin menjelaskan, bahwa diperlukan langkah-langkah untuk mendistribusikan zakat agar tepat sasaran melalui rapat pleno, namun Afdloluddin tidak menjelaskan secara rinci langkahlangkah tersebut. Wati menjelaskan terdapat dua langkah untuk mendistribusikan zakat, yaitu melakukan survei dan memilah calon penerima zakat.

Ketiga, studi mengenai program pada pendistribusian dana zakat disetiap lembaga amil zakat milik pemerintah dan lembaga amil zakat swasta. Studi tersebut dikaji oleh Antika ${ }^{23}$, Maskuroh ${ }^{24}$, Zabadi $^{25}$, Elman $^{26}$, Mukti ${ }^{27}$, Emirushalih ${ }^{28}$, dan Fakhriah $^{29}$. Perbedaan studi mereka terletak pada program dalam mendistribusikan dana zakat, namun Antika dan Maskuroh mempunyai

Undang No. 23 Tahun 2011)", Skripsi (Surakarta: Hukum Ekonomi Syariah IAIN Surakarta, 2017), hal. 122

23 Prihar Yusmi Antika, "Strategi Pendistribusian Zakat melalui Program Jatim Peduli di BAZNAS Provinsi Jawa Timur" Skripsi (Surabaya: Manajemen Dakwah UIN Sunan Ampel, 2019), hal. 68

24 Ira Nikmatul Maskuroh, "Penyaluran Zakat Produktif pada BAZNAS Kota Semarang”, Skripsi (Semarang: Ekonomi Islam UIN Walisongo, 2019), hal. 59

25 Ahmad Fairuz Zabadi, "Penyaluran Dana Zakat untuk Program Beasiswa Dhuafa pada Darunnajah Charity Jakarta Selatan" Skripsi (Jakarta: Manajemen Dakwah UIN Syarif Hidayatullah, 2018), hal. 53

26 Syaipudin Elman, "Strategi Penyaluran Dana Zakat BAZNAS melalui Program Pemberdayaan persamaan pada program-programnya. Antika menjelaskan terdapat lima program pada BAZNAS Jatim, yaitu Jatim Makmur, Jatim Cerdas, Jatim Sehat, Jatim Taqwa, Jatim Peduli, sedangkan Maskuroh juga menjelaskan terdapat lima program pasa BAZNAS Kota Semarang, yaitu Semarang Cerdas, Semarang Makmur, Semarang Sehat, Semarang Peduli, dan Semarang Taqwa. Zabadi menjelaskan terdapat tiga program pada lembaga Darunnajah Charity, yaitu beasiswa dhuafa, posko bencana alam, bakti sosial. Elman menjelaskan terdapat enam program pada BAZNAS, yaitu bantuan kemanusiaan, bantuan kesehatan, bantuan pendidikan, bantuan ekonomi, bantuan dakwah, dan masyarakat mandiri. Mukti menjelaskan terdapat empat program pada LAZNAS Baitul Mal Kudus, yaitu program pendidikan, program dakwah, program sosial, dan program ekonomi. Emirushalih menjelaskan terdapat lima program pada UPZ Majelis Ta'lim Telkomsel, yaitu kesehatan, ekonomi, dakwah, lingkungan, dan pendidikan. Fakhriah menjelaskan terdapat empat program pada BAZNAS

Ekonomi”, Skripsi (Jakarta: Ekonomi Islam UIN Syarif Hidayatullah, 2015), hal. 68

27 Ali Mukti, "Studi Analisis Penyaluran Zakat melalui Program Kampung berkah Mandiri di LAZNAS Baitul Maal Hidayatullah Cabang Kudus", Skripsi (Semarang: Ekonomi Islam IAIN Walisongo, 2015), hal. 46

28 Fajrialdy Emirushalih, "Optimalisasi Pendayagunaan Zakat melalui Program Beasiswa Majelis Ta'lim Telkomsel (Studi Kasus pada UPZ Majelis Ta'lim Telkomsel)", Skrpsi (Jakarta: Ekonomi Syariah UIN Syarif Hidayatullah, 2017), hal. 51

29 Dini Fakhriah, "Efektivitas Penyaluran Dana Zakat di BAZNAS Kota Bekasi dalam Peningkatan Pendidikan melalui Program Bekasi Cerdas", skripsi (Jakarta: Ekonomi Islam UIN Syarif Hidayatullah, 2016), hal. 50 
kota Bekasi, yaitu Bekasi Berdaya, Bekasi Cerdas, Bekasi Sehat, dan Bekasi Ihsan.

$$
\text { Keempat, studi mengenai }
$$

manajemen pendistribusian dana zakat. Studi tersebut dikaji oleh $\mathrm{Nisa}^{30}$, Novitasari $^{31}$, Duriyah ${ }^{32}$,

Al-Fadlil ${ }^{33}$, dan Bastiar ${ }^{34}$. Secara umum, mereka menjelaskan manajemen menegenai fungsi-fungsi manajemen. Penelitian tentang pendistribusian dana zakat ini termasuk dalam dimensi ketiga. Pada dimensi ketiga, perbedaan penelitian yang dilakukan oleh Anyika, Maskuroh, Zabadi, Elman, Mukti, Emirushalih, dan Fakhriah dengan penelitian ini terletak pada program untuk mendistribusikan dana zakat.

\section{Metode}

Peneliti menggunakan pendekatan kualitatif dan menggunakan jenis penelitian studi kasus. Penelitian ini menggunakan wawancara, observasi, dan dokumentasi untuk teknik pengumpulan data. Jenis data yang digunakan peneliti adalah data primer dan data sekunder. Dalam proses pengumpulan data, peneliti melakukan trianggulasi data dan meningkatkan ketekunan. dalam hal tersebut, peneliti menggunakan trianggulasi sumber dan trianggulasi metode. Hal tersebut dilakukan peneliti

\footnotetext{
30 Anis Khoirun Nisa, "Manajemen Pengumpulan dan Pendistribusian Dana Zakat, Infaq, dan Shadaqah di Lembaga Amil Zakat, Infaq, dan Shadaqah Masjid Agung (LAZISMA) Jawa Tengah, Skripsi (Semarang: Manajemen Dawah UIN Walisongo, 2015), hal 88

31 Desmi Novitasari, "Manajemen Pendistribusian Zakat di Badan Amil Zakat Nasional (BAZNAS) Provinsi Bengkulu", Skripsi (Bengkulu: Manajemen Zakat dan Wakaf IAIN Bengkulu, 2018), hal. 83

32 Siti Dutiyah, "Manajemen Pendistribusian Zakat (Studi Kasus pada LAZISMU PDM Kota Semarang)", Skripsi (Semarang: Ilmu Ekonomi Islam UIN Walisongo, 2015), hal. 63
}

untuk menguji keabsahan data dan digunakan untuk pengecekan data. Selain itu, peneliti juga melakukan pemilahan data, menyajikan data, dan menganalisis data secara sistematis.

\section{Hasil dan Pembahasan}

Pendistribusian merupakan kegiatan pemasaran yang berusaha untuk mempercepat dan mempermudah dalam menyampaikan barang dan jasa dari produsen kepada konsumen, sehingga penggunannya sesuai dengan yang diperlukan. ${ }^{35}$ Pendistribusian pada perusahaan mempunyai pihak-pihak yang berkontribusi pada penyampaian produk kepada konsumen. Hal ini dilakukan agar produk sampai kepada konsumen. ${ }^{36}$

Pada BAZNAS Jawa Timur, pendistribusian pada program beasiswa SKSS adalah diberikan secara langsung kepada mustahik. Pemberian secara langsung ini adalah melalui transfer ke pihak mustahik penerima beasiswa SKSS. Hal ini dilakukan, karena mustahik penerima beasiswa SKSS sudah mempunyai ATM. Hal ini juga dilakukan, supaya BAZNAS Jawa Timur mempermudah mahasiswa dalam membayar UKT. Mustahik juga tidak perlu bolak-balik ke BAZNAS Jawa Timur, akan tetapi mustahik sesekali untuk ke

33 Ahmad Haidir Al-Fadlil, "Manajemen Pendistribusian Dana ZIS pada Program Beasiswa di BAZDA Kota Tangerang Selatan”, Skripsi (Jakarta: Ekonomi Islam UIN Syarif Hidayatullah, 2014), hal. 82

34 Andar Bastiar, "Manajemen Distribusi Dana Zakat dalam Program Kantin Sekolah Sehat (Studi Kasus di BAZNAS Kabupaten Banyumas)", Skripsi (Purwekerto: Ekonomi Syariah IAIN Purwekerto, 2017), hal, 101

35 Fendy Tjiptono, Strategi Pemasaran, (Yogyakarta: ANDI, 2001), hal. 185

36 Ari Setiyaningrum, Jusuf Udaya, dan Efendi, Prinsip-Prinsip Pemasaran, (Yogyakarta: ANDI, 2015), hal. 158 
BAZNAS Jawa Timur untuk keperluan administrasi. Keperluan tersebut adalah penandatanganan pencairan saja. BAZNAS Jawa Timur memberikan secara langsung kepada mustahik SKSS yang mendaftarkan dirinya di BAZNAS Jawa Timur.

Pendistribusian beasiswa SKSS pada BAZNAS Jawa Timur juga dapat melalui BAZNAS Kabupaten di seluruh provinsi Jawa Timur. BAZNAS Kabupaten ini menyalurkan kepada mustahik SKSS di luar kota Surabaya dan Sidoarjo. BAZNAS Kabupaten akan memberikan kepada mahasiswa penerima beasiswa SKSS juga melalui tranfer. Hal ini juga memberikan kemudahan bagi mustahik dalam membayar UKT mereka.

\section{Penutup}

\section{A. Simpulan}

Dari hasil analisa dan pembahasan tentang pendistribusian zakat pada program beasiswa satu keluarga satu sarjana di Badan Amil Zakat Nasional Surabaya, penulis dapat mengambil kesimpulan. Kesimpulan tersebut adalah pendistribusikan zakat yang sudah terkumpul di BAZNAS Jawa Timur. Pendistribusian zakat ini diberikan secara langsung kepada mahasiswa penerima beasiswa SKSS. Pendistribusian secara langsung ini adalah melalui transfer. Dana zakat yang sudah terkumpul, kemudian dana tersebut diberikan secara langsung kepada mahasiswa penerima beasiswa. Pendistribusian zakat pada program beasiswa SKSS ini juga melalui BAZNAS Kabupaten. BAZNAS Kabupaten akan menyalurkan dana zakat selain di kota Surabaya dan Sidoarjo. BAZNAS Kabupaten tersebut juga akan menyalurkan dana zakat kepada mahasiswa penerima beasiswa melalui transfer.

\section{B. Saran}

Perlu penelitian lebih lanjut mengenai pendistribusian zakat pada program beasiswa Satu Keluarga Satu Sarjana di Badan Amil Zakat Nasional Jawa Timur. Pendistribusian zakat pada beasiswa SKSS perlu dilakukan untuk menyalurkan zakat kepada mustahik yang berhak menerimanya. Hal tersebut dilakukan, agar kaum duafa terbantu meneruskan pendidikannya dan menyejahterakan perekonomian Jawa Timur.

Penelitian ini dapat diimplementasikan untuk Badan Amil zakat Nasional Jawa Timur terutama kepala pendistribusian. Kepala pendistribusian hendaknya memperhatikan tugas dari relawan terutama relawan SKSS. Tujuan hal tersebut, agar relawan SKSS memahami dengan benar tugas mereka dan memiliki rasa tanggung jawab sebagai relawan.

\section{Daftar Pustaka}

Abdullah, Thamrin dan Francis Tantri. 2016. Manajemen Pemasaran. Jakarta: Grafindo

Afdloluddin, "Analisis Pendistribusian Dana Zakat bagi Pemberdayaan Masyarakat (Studi Pola Lembaga Amil Zakat Dhompet Dhuafa Cabang Jawa Tengah)", Skripsi (Semarang: Ilmu Ekonomi Islam UIN Walisongo, 2015)

Agustina, Kukuh Dwi, "Penyaluran Dana Zakat di Badan Amil Zakat Nasional (BAZNAS) Kabupaten Kebumen Tahun 2015", Skripsi (Purwekerto: Akhwal AlSyakhsyiah IAIN Purwekerto) 
Al-Fadlil, Ahmad Haidir, "Manajemen Pendistribusian Dana ZIS pada Program Beasiswa di BAZDA Kota Tangerang Selatan", Skripsi (Jakarta: Ekonomi Islam UIN Syarif Hidayatullah, 2014)

Antika, Prihar Yusmi, "Strategi Pendistribusian Zakat melalui Program Jatim Peduli di BAZNAS Provinsi Jawa Timur" Skripsi (Surabaya: Manajemen Dakwah UIN Sunan Ampel, 2019)

Ardiansyah, M. Iqbal, "Pendistribusian Zakat pada Lembaga Amil Zakat Infaq dan Shadaqah (LAZIS) Alwasi' Universitas lampung", Skripsi (Lampung: Manajemen dakwah UIN Raden Intan, 2018)

Arif, Muhammad. 2012 Supply Chain Management. Yogyakarta: Budi Utama

Asri, Marwan. 1991. Marketing. Yogyakarta: AMP YKPN

Bahrudin, Makhfudl Bayu, "Efektifitas Penyaluran Zakat di BAZNAS Provinsi Jawa Timur", Skripsi (Surabaya: Ekonomi Syariah UIN Sunan Ampel, 2017)

Bastiar, Andar, "Manajemen Distribusi Dana Zakat dalam Program Kantin Sekolah Sehat (Studi Kasus di BAZNAS Kabupaten Banyumas)", Skripsi (Purwekerto: Ekonomi Syariah IAIN Purwekerto, 2017)

Dutiyah, Siti, "Manajemen Pendistribusian Zakat (Studi Kasus pada LAZISMU PDM Kota Semarang)", Skripsi (Semarang: Ilmu Ekonomi Islam UIN Walisongo, 2015)

Elman, Syaipudin, "Strategi Penyaluran Dana Zakat BAZNAS melalui Program Pemberdayaan Ekonomi”,
Skripsi (Jakarta: Ekonomi Islam UIN Syarif Hidayatullah, 2015)

Emirushalih, Fajrialdy, "Optimalisasi Pendayagunaan Zakat melalui Program Beasiswa Majelis Ta'lim Telkomsel (Studi Kasus pada UPZ Majelis Ta'lim Telkomsel)", Skrpsi (Jakarta: Ekonomi Syariah UIN Syarif Hidayatullah, 2017)

Fakhriah, Dini, "Efektivitas Penyaluran

Dana Zakat di BAZNAS Kota

Bekasi dalam Peningkatan

Pendidikan melalui Program

Bekasi Cerdas", skripsi (Jakarta:

Ekonomi Islam UIN Syarif

Hidayatullah, 2016)

Didin Fatihudin, Didin dan Anang Firmansyah.2019. Pemasaran Jasa. Yogyakarta: Deepublish

Ginting, Nembah F. Hartimbul. 2011. Manajemen Pemasaran. Bandung: Yrama Widya

Hakim, Edi Lukman, "Pola Distribusi

Dana Zakat Lembaga Amil Zakat Infaq dan Shadaqah (LAZISMA) Masjid Agung Jawa Tengah", Skripsi (Semarang: Ekonomi Islam IAIN Walisongo, 2011)

Kotler, Philip dan Nancy Lee. 2007. Pemasaran di Sektor Publik. Jakarta: Indeks

Limakrisna, Nandan. 2012. Manajemen Pemasaran Teori dan Aplikasi dalam Bisnis. Jakarta: Mitra Wacana Media

Maskuroh, Ira Nikmatul, "Penyaluran Zakat Produktif pada BAZNAS Kota Semarang", Skripsi (Semarang: Ekonomi Islam UIN Walisongo, 2019)

Mukti, Ali, "Studi Analisis Penyaluran Zakat melalui Program Kampung 
berkah Mandiri di LAZNAS Baitul Maal Hidayatullah Cabang Kudus", Skripsi (Semarang: Ekonomi Islam IAIN Walisongo, 2015)

Nisa, Anis Khoirun, "Manajemen Pengumpulan dan Pendistribusian Dana Zakat, Infaq, dan Shadaqah di Lembaga Amil Zakat, Infaq, dan Shadaqah Masjid Agung (LAZISMA) Jawa Tengah, Skripsi (Semarang: Manajemen Dawah UIN Walisong, 2015)

Novitasari, Desmi, "Manajemen

Pendistribusian Zakat di Badan Amil Zakat Nasional (BAZNAS) Provinsi Bengkulu", Skripsi (Bengkulu: Manajemen Zakat dan Wakaf IAIN Bengkulu, 2018)

Risnawati, "Kajian Pengelolaan dan Penyaluran Dana di BAZNAS Provinsi Sulawesi Selatan", Skripsi (Makassar: Ekonomi Islam UIN Alauddin, 2018)

Setiyaningrum, Ari, Jusuf Udaya, dan Efendi. 2015. Prinsip-Prinsip Pemasaran. Yogyakarta: ANDI

Susilowati, Handri, "Pelaksanaan Pendistribusian Zakat di BAZNAS Sumsel", Skripsi (Palembang: Manajemen Pendidikan Islam UIN raden Fatah, 2018)

Tjiptono, Fendy. 2001. Strategi Pemasaran. Yogyakarta: ANDI

Tjiptono, Fandy. 2014. Pemasaran Jasa. Yogyakarta: ANDI

Wati, Tanti Indah, "Metode Pengumpulan Zakat dengan Sistem ZISCO dan Media Online serta Pendistribusian Zakat di Yayasan Yatim Mandiri cabang Surakarta (Studi berdasarkan Undang-Undang No. 23 Tahun 2011)", Skripsi
(Surakarta: Hukum Ekonomi Syariah IAIN Surakarta, 2017)

Zabadi, Ahmad Fairuz, "Penyaluran Dana Zakat untuk Program Beasiswa Dhuafa pada Darunnajah Charity Jakarta Selatan" Skripsi (Jakarta: Manajemen Dakwah UIN Syarif Hidayatullah, 2018) 